\title{
Perceptions, Feelings, and Meanings of the Early Stress for the Adult with Depression: A Theoretical Model
}

\section{Carla Araujo Bastos Teixeira ${ }^{1}$, Maria Neyrian de Fátima Fernandes ${ }^{2,3^{*}}$, Raquel Cocenas da Silva ${ }^{4}$, Kelly Graziani Giacchero Vedana ${ }^{3}$, Edilaine Cristina da Silva Gherardi-Donato ${ }^{3}$}

\author{
${ }^{1}$ Medicine Department, CEUMA University, Campus Imperatriz, Imperatriz, Brazil \\ ${ }^{2}$ Nursing Coordination, Federal University of Maranhão, Imperatriz, Brazil \\ ${ }^{3}$ Psychiatric Nursing and Human Sciences Department, College of Nursing, University of São Paulo, \\ Ribeirão Preto, Brazil \\ ${ }^{4}$ Faculty of Philosophy, Sciences and Letters at Ribeirão Preto, Ribeirão Preto, Brazil \\ Email: *neyrian@usp.br
}

How to cite this paper: Teixeira, C.A.B., de Fátima Fernandes, M.N., da Silva, R.C., Vedana, K.G.G. and da Silva GherardiDonato, E.C. (2019) Perceptions, Feelings, and Meanings of the Early Stress for the Adult with Depression: A Theoretical Model. Open Journal of Nursing, 9, 1252-1266. https://doi.org/10.4236/ojn.2019.912091

Received: October 16, 2019

Accepted: December 16, 2019

Published: December 19, 2019

Copyright (c) 2019 by author(s) and Scientific Research Publishing Inc. This work is licensed under the Creative Commons Attribution International License (CC BY 4.0).

http://creativecommons.org/licenses/by/4.0/

\begin{abstract}
This study aimed to elaborate on theoretical model of the perceptions, feelings, and meanings of early stress for people with depression. To perform a qualitative study based on the Symbolic Interactionism and Grounded Theory, we interviewed 12 patients diagnosed with depression. It was structured a model based on "walking between traumatic childhood and the adult life with depression," integrating eight inter-articulated categories that represent the perceptions, feelings, and meanings of the experiences of the depressed individual with a history of early stress. The theoretical model constructed meanings and conditions that affect the individual from a traumatic childhood to depression in adulthood.
\end{abstract}

\section{Keywords}

Nursing, Mental Health, Psychological Stress, Child Abuse, Depression

\section{Introduction}

Mental disorders have multifactorial causes, among which the main are genetic, psychological, sociocultural, and political factors. Studies have shown that maternal mental disorder significantly affects child development and is a catalyst to mental disorders in adolescents [1] [2] [3].

In general, the risk exposures to within the family, such as a mental issue of the genitors and poverty conditions, configure as risk factors, increasing the 
vulnerability to develop damage to mental health [1] [2]. Likewise, abuse or negligence experienced in the early stages of development is also a negative factor for mental health. Traumatic events speed up the transitions to autonomy and abruptly end childhood, affecting the many processes that occur during development [3].

The impact of mental disorders on childhood and adolescence can act as a precursor to psychiatric and social issues in adult life. It is important to note that environmental and psychosocial factors can contribute more to mental illness than characteristic intrinsic to the individual, rebounding on the genetic processes and gene expression [4] [5]), although this aspect has not been exhaustively investigated.

Therefore, mental illness must not be considered an isolated event. There are internal and external factors that overcome the temporal barrier with repercussions over life. Thus, the early stress is characterized by adverse and traumatic events that occurred during childhood, a period in which essential brain structures are being formed, affecting the formation of many emotional, behavioral, social, affective, and physical spheres [6] [7] [8].

For children who experienced early stress situations, there were increased chances of developing depression in adolescence and adulthood. From one third to one-fourth of children in this situation, fill the depression criteria before completing 20 years of age, configuring a severe public health issue [9].

The occurrence of depression symptoms such as anxiety disorders and the abusive use of chemical substances is strongly associated with the presence of early stress [10] [11]. The exposure to mistreatments during childhood, such as negligence, is correlated to the reduction in the volume of grey matter in the brain of adolescents, behavioral changes, and mental health disorders [12].

In a meta-synthesis of qualitative studies that analyzed the relationship between early stress and the behavior of chemical dependence during adulthood, we verified that there are significant associations between them, as well as with the traumas of childhood and the tendency to violent behavior. Furthermore, the dependence on other forms, such as sex and gambling, were considered forms for coping with the traumas caused in childhood during adulthood [13].

Therefore, the role of stress on unbalancing the health-disease process is related to the multifactorial causes such as a stressful situation, the development stage, psychosocial support conditions, perception of the individual on the stressing situation, and the confrontation mechanisms along with the life experience.

Based on immersion into the scientific literature, we concluded that the studies demonstrate the association of early stress with the development of depression, but that the processes that lead from one extreme to the other are not yet clear. Therefore, we aimed at elaborating on a theoretical model to understand the perceptions, feelings, and meanings of early stress to individuals that experience traumas during childhood and become depressed adults. 


\section{Method}

The question of this research was: "what is the meaning of early stress for people who experience traumas during childhood and become depressed adults?" This research consists of a transversal study with a qualitative approach using the Grounded Theory (GT) as a methodological reference [14] and the Symbolic Interactionism (SI) as a theoretical reference [15].

The GT allows the construction of substantive theories based on the life experiences of individuals [16]. The SI is based on social interactions configures as a process that outlines human behavior. Its premise is that, when coming into contact with the other, the subject modifies his/her feelings and causes changes in random meanings [17]. The data collection and analysis co-occurred. Therefore, according to SI, the early stress is continuously defined and redefined by the person in a dynamic and interactional process.

The SI if traditionally considered a component of the theoretical foundations of the GT methodology [14], both presenting a reliable conceptual connection [18]. In this study, the GT was used to determine the methodological procedures, including the theoretical sampling, memos, constant comparative methods, codification and categorization, and theory generation. SI provides a theoretical mark for understanding how the meanings and the nature of the meanings constructed in social interactions. We based the study on the Consolidated Criteria for Reporting Qualitative Research (COREQ) to ensure a clear and understandable report [19].

Data collection occurred at a Psychosocial Care Center-CAPS III, located in the countryside of São Paulo, Brazil, which deliver care for people with mental disorders. The inclusion criteria were: legal age, undergo clinic or semi-intensive monitoring at the CAPS III with a clinical diagnosis of depression, present score on the Childhood Trauma Questionnaire (CTQ) for moderate to severe early stress. The exclusion criteria were: cognitive deficit, progressive/degenerative neurological disease, and mental retardation.

Patients in this study were recruited in person via researcher and workers from the CAPS III. The sample was made up of individuals who come to the CAPS III to get counseling on their depression. Twelve patients diagnosed with depression and selected from an analytical sampling process partook of this study, as proposed by the methodological reference employed [14]. In the first stage of collection, we referred 23 users to the initial interview and application of the CTQ, as well as the necessary feedback. Of these, 21 fulfilled the early stress measure established in the inclusion criteria. There were nine exclusions by withdrawal, that is, absences at the day scheduled for the interview, or voluntary withdrawal after receiving the explanations of the study. The approaches and interviews were conducted by the researcher, experienced in the field of nursing in mental health, to ensure the adequate management of the patients. We contacted the patients by telephone when we verified a withdrawal from the study. The users that attended the interview but did not reach the CTQ for moderate to severe 
early stress received feedback from the researcher regarding their situation and the non-participation of the study. The final sample consisted of 12 voluntary participants.

Recruitment continued until sampling frame requirements were met the data saturation and study objective reached on the studied phenomenon. The research was approved by the Research Ethics Committee (CAAE Process No.: 53782716.3.0000.5393). The interviewees signed a Free Consent Term, answered the Sociodemographic Questionnaire and health Conditions, CTQ, and a recorded in-depth interview.

The sociodemographic work and health conditions questionnaire elaborated with 27 questions: age, sex, schooling, civil status, religion, time period of working in the sector, time period working in the profession, number of employment, time of work, living arrangements, number of people who live in the residence, number of children, medical consultation in the last year, motive for the consultation, type of healthcare service, medication use, work leave, self-reported diseases, and use of alcohol and tobacco.

The reduced version of the CTQ [20], comprised by 28 items, answered in a Likert scale from 1 (never) to 5 (always) [21], ranges from 5 to 25 points and indicated the following subtypes of early stress: emotional, physical, and sexual abuse; and physical and emotional negligence. The core is the sum referent to each assertive of each dimension, totalizing five scores. For the individual considered as having undergone early stress during childhood, it is necessary to classify as moderate-severe or severe-extreme. The cutting point is defined by at least one of the five domains classified from moderate to severe: emotional abuse $\mathrm{CTQ}>$ or $=$ to 13; physical abuse CTQ $>$ or $=10$, sexual abuse CTQ $>$ or $=8$, physical negligence CTQ $>$ or $=15$, emotional negligence CTQ $>$ or $=10$ [20] [21].

\subsection{In-Depth Interview}

The research team designed the question to start the interview. The interview developed provided the flexibility to allow the emergence of new themes or changes in the question. The beginning of the in-depth interview was guided by the following assertive: "Today, let's talk about you and how you got here. You can take the time you need. You can start by telling me who you are..." was changed to: "What is your first memory from when you were a child?"

During the interviews, we included questions about the guiding topics based on theoretical concepts of evolution to clarify the studied phenomenon such as the experience during childhood and depression, contributing for understanding the functioning of the participant regarding the experiences reported, focusing on different behaviors, decision-making, and perspectives for the future. At the end of each meeting, participants received feedback on the information recorded, addressing the needs observed by the researcher.

The refusals occurred for many reasons, among which was the discomfort of unveiling intimate and often embarrassing situations to a stranger or not show 
up in the previously scheduled date. To preserve participants' anonymity, we used the denomination " $E$ " for the interviewees, followed by the number of the order in which the interviews conducted. The interviews lasted for an average of 60 minutes and conducted by the researcher in a private location.

\subsection{Data Analysis}

There are three critical stages to qualitative data analysis: Open coding-the emerging data were divided into analysis units and named with codes. The codes were compared among each other, observing the similarities and differences, generating temporary categories. Axial coding-the connections between categories and subcategories were examined. Selective coding-all the categories were aggregated, and we conducted the inventory analysis. To build the theory, we used to register the ideas and perceptions of the categories.

For the analysis, we used the procedures recommended by the GT, such as constant comparisons (to identify patterns and data variations), inquiries, reaction identification, and samplings based on theoretical concepts of evolution. The result of this process constitutes the development of a theoretical model of the investigated reality.

\section{Results}

Twelve patients with major depressive disorder took part in the individual interviews. All of them classified in the CTQ as severe to extreme. Most of them were women, divorced, and religious (Table 1).

Walking between a traumatic childhood and adult life with depression has represented the theoretical model of the lived experience. The experiences and meaning of the early stress for depression bearers were understood as a dynamic psychosocial process. The form in which the traumatic experiences were faced during childhood is reflected in behaviors that influence the formation of the being and outline how he/she places him/herself internally and externally in the adult life. Such a position concerning the adversities was considered significant for the process of mental illness and, in the present study, the development of depression.

This theoretical model integrates eight inter-articulated categories that represent the perceptions, feelings, and meanings present in the experience of the depressed individual with a history of early stress: 1) experiencing the early stress; 2) feeling treatment differentiation within the family; 3) assuming roles incompatible with his/her age; 4) building the self, 5) generalization of the discredit, hopelessness, and impotence; 6) interpreting the negative behavior of the parents; 7) experiencing depression; 8) use and abuse of psychoactive substances and domestic violence (Figure 1).

1) Experiencing early stress

It is the beginning of the process for prematurely leading with stress generating situations, suffering the first frustrations and fear/sorrow, followed by a traumatic experience. When narrating their perceptions as a child, the participant 
Table 1. Individual characteristics of participants $(n=12)$.

\begin{tabular}{|c|c|c|c|c|c|c|}
\hline Code & Gender & Age & $\begin{array}{l}\text { Marital } \\
\text { status }\end{array}$ & Religion & CTQ classification & CTQ subscale \\
\hline \multirow[t]{2}{*}{ E01 } & \multirow[t]{2}{*}{ Male } & \multirow[t]{2}{*}{36} & \multirow[t]{2}{*}{ Divorced } & \multirow[t]{2}{*}{ Agnostic } & Severe to extreme & $\begin{array}{l}\text { Emotional abuse, physical } \\
\text { neglect, and emotional neglect }\end{array}$ \\
\hline & & & & & Moderate to severe & Physical abuse \\
\hline \multirow[b]{2}{*}{ E02 } & \multirow[b]{2}{*}{ Female } & \multirow[b]{2}{*}{55} & \multirow[b]{2}{*}{ Divorced } & \multirow[b]{2}{*}{ Catholic } & Severe to extreme & Emotional abuse \\
\hline & & & & & Moderate to severe & $\begin{array}{l}\text { Physical neglect and } \\
\text { emotional neglect }\end{array}$ \\
\hline \multirow{2}{*}{ E03 } & \multirow{2}{*}{ Female } & \multirow{2}{*}{58} & \multirow{2}{*}{ Divorced } & \multirow{2}{*}{ Protestant } & Severe to extreme & $\begin{array}{l}\text { Emotional abuse and } \\
\text { emotional neglect }\end{array}$ \\
\hline & & & & & Moderate to severe & $\begin{array}{l}\text { Sexual abuse and physical } \\
\text { neglect }\end{array}$ \\
\hline \multirow[t]{2}{*}{ E04 } & \multirow[t]{2}{*}{ Female } & \multirow[t]{2}{*}{51} & \multirow[t]{2}{*}{ Married } & \multirow[t]{2}{*}{ Spiritism } & Severe to extreme & $\begin{array}{l}\text { Physical abuse, emotional } \\
\text { abuse, and emotional neglect }\end{array}$ \\
\hline & & & & & Moderate to severe & Physical neglect \\
\hline E05 & Female & 45 & Married & Catholic & Severe to extreme & $\begin{array}{l}\text { Physical abuse, emotional } \\
\text { abuse, sexual abuse, physical } \\
\text { neglect, and emotional neglect. }\end{array}$ \\
\hline E06 & Male & 59 & Divorced & Christian & Severe to extreme & $\begin{array}{l}\text { Emotional abuse and } \\
\text { physical neglect }\end{array}$ \\
\hline \multirow[t]{2}{*}{ E07 } & \multirow[t]{2}{*}{ Female } & \multirow[t]{2}{*}{30} & \multirow[t]{2}{*}{ Married } & \multirow[t]{2}{*}{ Catholic } & Severe to extreme & $\begin{array}{l}\text { Emotional abuse and } \\
\text { emotional neglect }\end{array}$ \\
\hline & & & & & Moderate to severe & Physical neglect \\
\hline E08 & Female & 31 & Married & Agnostic & Severe to extreme & $\begin{array}{l}\text { Physical abuse, emotional } \\
\text { abuse, sexual abuse, physical } \\
\text { neglect, and emotional neglect }\end{array}$ \\
\hline \multirow{2}{*}{ E09 } & \multirow{2}{*}{ Female } & \multirow{2}{*}{56} & \multirow{2}{*}{ Married } & \multirow{2}{*}{ Catholic } & Severe to extreme & $\begin{array}{l}\text { Physical abuse and sexual } \\
\text { abuse }\end{array}$ \\
\hline & & & & & Moderate to severe & $\begin{array}{l}\text { Emotional neglect and } \\
\text { emotional abuse }\end{array}$ \\
\hline \multirow[t]{2}{*}{ E10 } & \multirow[t]{2}{*}{ Female } & \multirow[t]{2}{*}{53} & \multirow[t]{2}{*}{ Divorced } & \multirow[t]{2}{*}{ Catholic } & Severe to extreme & $\begin{array}{l}\text { Emotional abuse, physical } \\
\text { abuse sexual abuse }\end{array}$ \\
\hline & & & & & Moderate to severe & Physical neglect \\
\hline E11 & Male & 52 & Single & Catholic & Severe to extreme & $\begin{array}{l}\text { Physical neglect and } \\
\text { emotional neglect }\end{array}$ \\
\hline & & & & & Moderate to severe & Physical abuse \\
\hline E12 & Female & 31 & Divorced & Agnostic & Severe to extreme & $\begin{array}{l}\text { Physical neglect and } \\
\text { emotional neglect }\end{array}$ \\
\hline
\end{tabular}

defines the stressful situations and attributes a negative sense to it, reacting according to the limited resources he/she possesses.

[...] My father was addicted to drugs, my mother hit me. [...] Then, she would wake me at night hitting me, she took me to the bathroom, turned the shower on, and put me under the shower, in the cold water. Since I was very young, I stayed under that cold water. I remained there shrunk, shivering" (E01). 


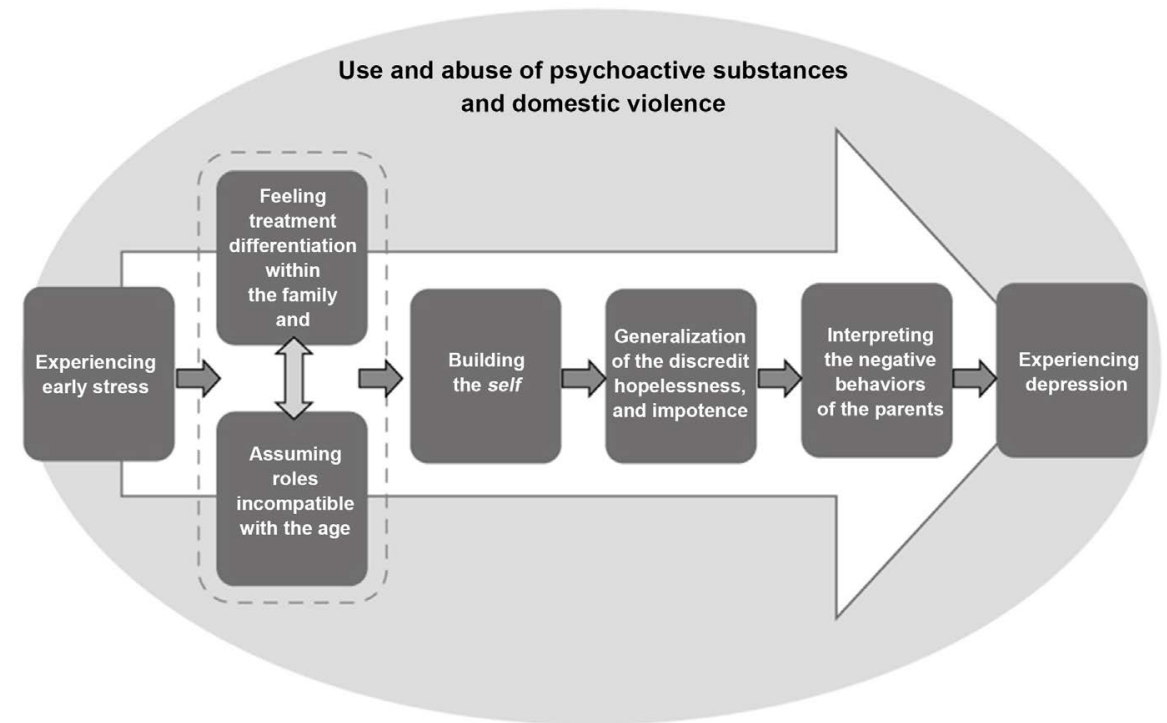

Figure 1. Walking between a traumatic childhood and the adult life with depression and the eight categories of the theoretical model. 1) Experiencing the early stress; 2) Feeling treatment differentiation within the family; 3) Assuming roles incompatible with his/her age; 4) Building the self, 5) Generalization of the discredit, hopelessness, and impotence; 6) Interpreting the negative behavior of the parents; 7) Experiencing depression; 8) Use and abuse of psychoactive substances and domestic violence.

[...] "There was always Fighting. It was almost every day. Sometimes we lay to sleep at night, and at night it began early morning again. How often I woke up frightened. Then, I would cry. Because you're a child, you're afraid of things happening. You're going to kill, right? You're going to hit, are you!? Hurt??... be afraid!" (E03).

The context in which the early stress develops can be considered relevant in the form in which the child deals with their own experiences. Insofar as the environment becomes adverse, with verbal aggression, physical aggression, physical and emotional negligence, the child incorporates behavioral patterns with negative meaning. The meaning attributed to these experiences directly affects the form of interacting with oneself and the world.

2) Feeling treatment differentiation within the family and 3) assuming roles incompatible with the age

These categories unveil perceptions that co-occur during the mental illness process. They do not follow a chronological order, thus, appear concomitantly, among the traumatic experiences of childhood and adolescence. The focus is on the perception that the parents perform an inadequate treatment and that the same does not occur to other family members.

[...] "And my mother went to São Paulo and forgot about me, understand? Because M. I (twin sister) is the prettier [...] every time, any problem [...] M. I. went with her. She lived and stayed together (with the mother) there. And I and L. (brother) stayed behind [...] I was always left for later" (E02). 
[...] "the problem was I. My whole life, the problem was I. [...] My mother and brother left hugging, and I left alone, as if I was to blame" (E08).

[...] "She always says my mother gave me more attention. But I was younger. [...] "I didn't ask to be born" [...]" (E04).

The different treatment by the parents/caretakers is placed in a general context of meaning, marked by both the care perceived as deficient and excessive care. The perception of the dissonance between treatments within the family generates loss with changes in self-esteem.

Regarding the category "assuming roles incompatible with the age", the focus is the identification of roles performed within the family. The roles performed within the family are soon perceived as an extra load of stress and responsibility, overcoming the role of the child in the family context.

[...] "I started having responsibilities since I was small. I didn't have time for things, for play, for anything. I had school meetings, I solved the class meeting and went to my brother's teacher [...] And every time he had to go to the doctor, I took him. So far as the doctor said: 'ah, the little mother brought the baby'. He started to call me little mother" (E03).

[...] "I think I was never a child. I suffer since I was a child, I am manipulated since I was a child." (E05).

[...] "I had to drop out of school very early to help my family, right?! Help my parents at the farm, I also polished shoes [...] when I was young" (E11).

The interviewees demonstrated feeling deprived of childhood, as a period that was unduly experienced due to the parental demands, regarding the lack of playing, involvement with groups of friends, and the interruption of their studies. The subject finds him/herself caring for their siblings, solving interfamily problems, trying to resolve issues regarding home maintenance, exceeding their physical and psychic capabilities.

4) Building the self

This category gives segment to the process of "walking" despite the experiences from childhood. The focus if the perception of the individual with him/herself based on the social interactions experienced. We observed that the selfis built and the significance of the interaction with others in the exchange of meaning and relations with the world occurs from building oneself.

[...] "As in bad examples in the family. This was normal in our daily life. We always chose the easiest path because there was never anyone to direct us, and we end up being involved with drugs, selling drugs, stealing, these things [...] So, these are things that happen in our lives that... that I believe that even today, even when I say that I don't want to connect 'this to that' (referring to the past with the present)" (E01).

[...] "Then after we grew, came adolescence and I started seeing the difference. The difference is [...] It went on. So I think the block came from the time at school" (E02).

[...] "I hold sorrow. I don't like being this way, I grew up like this, I didn't want to be this way, but, unfortunately, I am" (E10). 
The individual perceives the early stress as negative in the process of building the self, with intense changes. It remits to the situation experienced during childhood to the sensation that something intense occurred in his/her life, reflecting the disorganization of the functioning of life. The meanings attributed to the early stress are built around serious relationship issues within the family environment, of which consequences constitute the daily life during childhood. The perception of the childhood experiences was reinforced in every experience, damaging the formation of affection bonds between the family members.

5) Generalization of the discredit, hopelessness, and impotence

This category is subsequent and focused on the form in which the individual deals with life decisions and assumes a passive stance regarding decision-making. The subject sees him/herself limited, passive. There is hopelessness in the form of leading live, as if the resources used during childhood, those more instinctive, were the only resources that could be used to face adult life.

[...] "I didn't even pick the names of my children [...] I accepted everything!"(E02).

[...] "There was this moment in which I, I began to want to have some planning in life. But it was only an illusion that I believe that in a little while will also be gone. [...] And I lived life as I could. In life, I never had a choice [...]" (E01).

The individual perceives him/herself with no control, where daily decisions are viewed from an external perspective, regardless of the level of complexity. It is as if the individual does not participate in the decision-making process. There is a tendency to discredit the possibility of a change of internal functioning. They seem to establish the feeling of impotence concerning the situations as if the development paralyzed into the period of childhood.

6) Interpreting the negative behaviors of the parents

The focus of this category consists of behavioral models seized during the formation of the self.

[...] "One day my son argued with his father, 'I saw you hit my mother a lot. Touch her and see what happens. Touch her and see what happens'. He said: 'P II beat you in half" (E04).

[...] "Look what you did with her life since she was little. If my mother is what she is, it is because you didn't support my mother" (E05).

We verified that the individual processing and interpreting the experiences, choosing, checking, grouping, and regrouping the set of behaviors through a formative process that results in a symbolic set used as a directive for behaving in adult life. The behavior with a negative sense may or may not be perpetrated to the children, though it is always perceived as unfavorable.

7) Experiencing depression

The final category of the theoretical model is: "Walking between a traumatic childhood and the adult life with depression." The focus is on how the individual represents the experience of depression. The depression psychopathy is considered an unfolding of the interactions experienced by the subject during his/her life. An entire symbolical set is built and rebuilt over the social interactions. The 
reality is interpreted for the reality symbolically experienced to be a reference in the development of thinking and acting.

[...] "There are days in which I want to die, to vanish, to disappear, throw myself into a hole. I don't know anything. Sometimes I lie down and keep asking: 'God take me, I've lived enough, that's enough! I'm tired!' I cry since I was a child! (continues to cry) Ever since I can remember. My whole life was crying. [...] I have suffered my whole life. I was mistreated by my mother my entire life. And today, I depend on and live in her house. I can't find a job. And worse, I can't leave her house." (E03).

[...] "I say that I have depression since I was a child because at that time there were no educators, there was no psychologist to help us" (E04).

[...] "I have crying bouts, I want to die, I can't take it anymore, I don't know what to do. [...] I have closed myself too much, and I have closed myself to live, I have closed myself to everything" (E10).

The end of the line represents depression. The subject identifies itself at the end of a long path, of which the end is the depressive state as if he/she were destined to suffer. It is as if the chronologicalline was running out, and the following phase is death. Death can symbolize the end of an arduous journey of suffering that began during childhood.

In a general context of meaning, the individual considers him/herself as impotent regarding the depressive symptomatology and the social changes unleashed. The suffering, lack of control over oneself, and lack of perspective are key-terms for understanding how depression overcomes the organic standards. It is not only a disease, but it is also the end of a process.

8) Use and abuse of psychoactive substances and domestic violence

This category was highlighted from the theoretical model as a different category since it emerged as a background during the process described, presenting a differentiated relation to the remaining categories

[...] "And was beat, he drank, and he beat me" (E10).

[...] "He (husband) drank, he arrived drunk, he fought, he argued... [...]" (E02).

The use and abuse of substances, when associated with domestic violence in adult life, were two factors that pervaded the daily life of the interviewees, in a shaded manner, behind the experiences and symbologies developed.

Whenever the "use and abuse of substances" occurred in the narrative, it was associated with "domestic violence in adult life." These factors occurred marginalizing the process as a whole. That which most demands attention is the fact that the substance abuse has always been there, connecting the experiences of the participants.

\section{Discussion}

To understand the meaning of early stress in individuals that experience traumas during childhood and become depressed adults, we verified that the characteristics found in the studied sample converges with the scientific evidence that point 
to individuals exposed to abuse and negligence, who use and abuse of substances, are among the vulnerable to the development of many mental disorders such as depression and bipolar affective disorder [22].

The presence of abuse and negligence during childhood was evident in the reports and the CTQ score. The subtypes of early stress were prominent by the frequency of occurrence despite having scored for other types of abuse and negligence. Based on the data found, a perspective emerges, given that the adults that suffered multiple types of abuse, including physical and sexual, during childhood and adolescence, emphasized a negative feeling strongly related to the emotional sphere.

The emotional sphere declared during the interviews, primarily related to the decrease or lack of care, attention, and love, perceived as the factors that most unleash early stress. In this regard, the literature indicates that the higher the emotional parental negligence is, the higher the blood levels of hormones related to stress act on the HPA [23]. The children with experiences of emotional abuse and negligence are those who receive the least attention from family members and professionals, leading to a prognostics of mental suffering in the long-term [4] [5] [22].

It is known that children passively accept parental abuse with no attempt at retaliation [24]. It is a form of representing love and respect. For these children, undergoing abuse was a part of the process of being a child. When justifying the punishments, they define the trauma as culturally accepted. We also verified that the development and capacity of processing family interactions are damaged, thus perpetuating the vulnerability standards to the adults, unleashing a vicious cycle of maladjusted behavior [24].

There are difficulties in tracking the early stress in periods close to their occurrence since, when children, in addition to having insufficient internal resources, the individuals may not have comparison standards to recognize traumatic events. There are also difficulties related to the scarcity of psychological stress for measuring childhood trauma [25], the complexity of early stress, and characteristics of the child self-report that can compromise their reliability [25] [26] [27].

The report given by the interviewees demonstrated the use/abuse of substances as a strategy for coping. However, this strategy is inefficient and can cause more negative consequences for the individual and other members of the family and social conviviality.

The use/abuse of substances is configured as an attempt to decrease the emotional and mental pain caused by traumatic and violent experiences. In another study, the individuals revealed that the pain caused by traumatic experiences mitigated by the use of alcohol [28]. Furthermore, the perception of parental care is precarious and can be perceived as a relevant factor for the susceptibility to the biological changes essential to childhood development, generating a rick for the use/abuse of substances [23].

Despite the different life experiences, childhood is considered crucial in the 
trajectory of the individual afflicted by early stress since it causes profound changes that lead to the disorganization of the form of life functioning. There is the perception of being cornered by depression, which insidiously steals the individual's strength. This process is seen as slow imprisonment. The individual feels him/herself increasingly pushed down to a place with concrete surroundings from which there is no escape. Therefore, he/she seems to spare their debilitated strength, losing ground to another "being", the jailer, depression.

The early stress seems to impact the construction of the self. Although the meanings are reconstructed in a dynamic interactional process, this study proposes that traumatic interactions that occur during childhood can favor the perpetuation and generalization of the meanings of self, marked by hopelessness, impotence, discredit, and difficulty in decision-making [15]. Such aspects can be clinically relevant since the hope the individual has on what the future might bring can affect his/her self-esteem, emotion, and motivation [29].

This study unveiled a negativist perspective of the traumatic experiences and perpetrated this view over life. The histories shared are marked by suffering, sadness, and by the absence of empowerment. The clinical manifestations of depression reinforce this view of self and the world, construed since childhood. Such a scenery fosters reflections of the space for redefining these stories in the sense of constructing a rereading of the individual's existence, which allows the use of a more positive view. This is similar to a unifying theoretical framework that showed how early-life stress can induce long-term changes in behavior leading to vulnerability to cognitive and emotional disorders [30].

The symbolic interactionism contributes to a new and profound perspective on the stressing facts experienced during childhood and its repercussions on human development and, overall, on adult life of the individual. Understanding the complexity of the facts that influence depression in adult life and its relations with the traumatic events of childhood is crucial to the practice of professionals that perform with human suffering and the mental illnesses related to them. The development of support practices is necessary to protect individuals since childhood by allocating the resources required to prevent the emergence of depression in adult life.

It is fundamental to implement successful treatment interventions to address the specific psychiatric needs of abused children and adults with early life stress. Besides, policies to design and implement educational programs that reduce the unacceptably high rate of child abuse and neglect in our society and worldwide are necessary preventive measures [31].

This study was limited by the fact of not better elucidating the relation of childhood trauma with the origins of depression. Another limitation derives from including depresses individuals only, disregarding the cases of people that have suffered early stress but did not develop depression in life.

\section{Conclusions}

The early stress was explored and analyzed from the perspective of depressed in- 
dividuals, users of specialized service. The information obtained substantiated the elaboration of a theoretical model that corresponds to the process the subject undergoes, from the traumatic experiences during childhood to the depression as a closure. The theoretical model "walking between traumatic childhood and the adult life with depression" symbolizes the form in which the experiences were understood by the subjects themselves, molding their set of symbols expressed in feelings and behaviors.

The results obtained demonstrate that the therapeutic strategies that contemplate only the depression symptomatology are insufficient to the needs of the depressed individual. Rearranging the focus of the depression symptoms to organize the "being" may be a viable therapeutic path. Another relevant point is the prevention of early stress by implementing actions based on approaches that consider the familial influence to unleash it by identifying the abuses and negligence still during childhood.

The investigation of early stress fosters the need for effective interventions to prevent mental illness and the treatment of children and adolescents afflicted by stress. The study indicates target relations, contexts, and situations for planning strategies that can be offered by nursing for the care of children and adolescents and guide the need for receiving adults diagnosed with depression.

\section{Acknowledgements}

Supported by Conselho Nacional de Desenvolvimen to Científico e Tecnológico (CNPq), Brazil.

\section{Conflicts of Interest}

The authors declare no conflicts of interest regarding the publication of this paper.

\section{References}

[1] Harold, G., Acquah, D., Sellers, R., Chowdry, H. and Feinstein, L. (2016) What Works to Enhance Inter-Parental Relationships and Improve Outcomes for Children. University of Sussex, London.

[2] Pereira, D.C., Ruzzi-Pereira, A., Pereira, P.E. and Trevisan, E.R. (2014) Desempenho ocupacional de adolescents de um Centro de Atenção Psicossocial Infanto-juvenil (CAPSI). Revista de Terapia Ocupacional da Universidade de São Paulo, 25, 11-17. https://doi.org/10.11606/issn.2238-6149.v25i1p11-17

[3] Sanders, J., Munford, R., Thimasarn-Anwar, T., Liebenberg, L. and Ungar, M. (2015) The Role of Positive Youth Development Practices in Building Resilience and Enhancing Wellbeing for at-Risk Youth. Child Abuse \& Neglect, 42, 40-53. https://doi.org/10.1016/j.chiabu.2015.02.006

[4] Thiengo, D.L., Cavalcante, M.T. and Lovisi, G.M. (2014) Prevalence of Mental Disorders among Children and Adolescents and Associated Factors: A Systematic Review. Jornal Brasileiro de Psiquiatria, 63, 360-372. https://doi.org/10.1590/0047-2085000000046

[5] Cicchetti, D. (2016) Socioemotional, Personality, and Biological Development: Illu- 
strations from a Multilevel Developmental Psychopathology Perspective on Child Maltreatment. Annual Review of Psychology, 67, 187-211. https://doi.org/10.1146/annurev-psych-122414-033259

[6] Martins, C.M., Tofoli, S.M.C., Baes, C.V.W. and Juruena, M.F. (2011) Analysis of the Occurrence of Early Life stress in Adult Psychiatric Patients: A Systematic Review. Psychology \& Neuroscience, 4, 219-227. https://doi.org/10.3922/j.psns.2011.2.007

[7] Martins, C.M., Baes, C.V.W., Tofoli, S.M.C. and Juruena, M.F. (2014) Emotional Abuse in Childhood Is a Differential Factor for the Development of Depression in Adults. The Journal of Nervous and Mental Disease, 202, 774-782. https://doi.org/10.1097/NMD.0000000000000202

[8] Pinto, A.C., Luna, I.T., Sivla, A.D., Pinheiro, P.N. and Braga, V.A. (2014) Risk Factors Associated with Mental Health Issues in Adolescents: An Integrative Review. Revista da Escola de Enfermagem da USP, 48, 555-564. https://doi.org/10.1590/S0080-623420140000300022

[9] Mello, M.F., Faria, A.A., Mello, A.F., Carpenter, L.L., Tyrka, A.R. and Price, L.H. (2009) Maus-tratos na infância e psicopatologia no adulto: Caminhos para a disfunção do eixo hipotálamo-pituitária-adrenal. Revista Brasileira de Psiquiatria, 31, 41-48. https://doi.org/10.1590/S1516-44462009000600002

[10] Konradt, C.E., Jansen, K., Magalhães, P.V., Pinheiro, R.T., Kapczinski, F.P., Silva, R.A., et al. (2013) Early Trauma and Mood Disorders in Youngsters. Revista de Psiquiatria Clínica. São Paulo, 40, 93-96. http://hdl.handle.net/10183/107471 https://doi.org/10.1590/S0101-60832013000300003

[11] Lijffijt, M., Hu, K. and Swann, A.C. (2014) Stress Modulates Illness-Course of Substance Use Disorders: A Translational Review. Frontiers in Psychiatry, 5, 83. https://doi.org/10.3389/fpsyt.2014.00083

[12] Walsh, N.D., Dalgleish, T., Lombardo, M.V., Dunn, V.J., Van Harmelen, A.L., Ban, M., et al. (2014) General and Specific Effects of Early-Life Psychosocial Adversities on Adolescent Grey Matter Volume. NeuroImage: Clinical, 4, 308-318. https://doi.org/10.1016/j.nicl.2014.01.001

[13] Teixeira, C.A., Lasiuk, G., Barton, S., Fernandes, M.N.F. and Gherardi-Donato, E.C. (2017) An Exploration of Addiction in Adults Experiencing Early-Life Stress: A Metasynthesis. Revista Latino-Americana de Enfermagem, 25, e2939. https://doi.org/10.1590/1518-8345.2026.2939

[14] Strauss, A. and Corbin, J. (2008) Pesquisa qualitativa: TécnicaS e procedimentos para o desenvolvimento da teoria fundamentada. 2a Edition, Artmed, Porto Alegre.

[15] Blumer, H. (1998) Symbolic Interacionis. Perspective and Method. University of California Press, Berkeley, CA.

[16] Macdonald, M. and Schreiber, R.S. (2001) Constructing and Deconstructing: Grounded Theory in a Postmodern World. In: Schreiber, R.S. and Stern, P.N., Eds., Using Grounded Theory in Nursing, Springer Publishing Company, New York, 35-53.

[17] Dupas, G., Costa, O.I. and Alcoforado, T.N. (1997) The Importance of Symbolic Interacionism in Nursing Practice. Revista da Escola de Enfermagem da USP, 31, 219-226. https://doi.org/10.1590/S0080-62341997000200004

[18] Handberg, C., Thorne, S., Midtgaard, J., Nielsen, C.V. and Lomborg, K. (2015) Revisiting Symbolic Interactionism as a Theoretical Framework Beyond the Grounded Theory Tradition. Qualitative Health Research, 25, 1023-1032. https://doi.org/10.1177/1049732314554231 
[19] Tong, A., Sainsbury, P. and Craig, J. (2007) Consolidated Criteria for Reporting Qualitative Research (COREQ): A 32-Item Checklist for Interviews and Focus Groups. International Journal for Quality in Health Care, 19, 349-357. https://doi.org/10.1093/intqhc/mzm042

[20] Bernstein, D.P., Stein, J.A., Newcomb, M.D., Walker, E., Pogge, D., Ahluvalia, T., et al. (2003) Development and Validation of a Brief Screening Version of the Childhood Trauma Questionnaire. Child Abuse \& Neglect, 27, 169-190. https://doi.org/10.1016/S0145-2134(02)00541-0

[21] Grassi-Oliveira, R., Stein, L.M. and Pezzi, J.C. (2006) Translation and Content Validation of the Childhood Trauma Questionnaire into Portuguese language. Revista de Saúde Pública, 40, 249-255. https://doi.org/10.1590/S0034-89102006000200010

[22] Syed, S.A. and Nemeroff, C.B. (2017) Early Life Stress, Mood, and Anxiety Disorders. Chronic Stress, 1. https://doi.org/10.1177/2470547017694461

[23] Somaini, L., Donnini, C., Manfredini, M., Raggi, M.A., Saracino, M.A., Gerra, M.L., et al. (2011) Adverse Childhood Experiences (ACEs), Genetic Polymorphisms and Neurochemical Correlates in Experimentation with Psychotropic Drugs among Adolescents. Neuroscience \& Biobehavioral Reviews, 35, 1771-1778. https://doi.org/10.1016/j.neubiorev.2010.11.008

[24] Bittar, D.B., Spanó, A.M., Iossi, M.A. and Souza, E.M.T. (2012) Intrafamily Violence against Children and Adolescents from the Perspective of Aggressive Mothers. Revista Eletrônica de Enfermagem, 14, 771-778.

[25] Vanaelst, B., De Vriendt, T., Huybrechts, I., Rinaldi, S. and De Henauw, S. (2012) Epidemiological Approaches to Measure Childhood Stress. Paediatric and Perinatal Epidemiology, 26, 280-297. https://doi.org/10.1111/j.1365-3016.2012.01258.x

[26] Teixeira, C.A., Santos, E.T.C., Gherardi-Donato, E.C.S., Reisdorfer, E., Carvalho, A.M. and dos Santos, P.L. (2015) Testes psicológicos utilizados para avaliare stressen a criança: Uma revisão integrativa. Arquivos de Ciências da Saúde da UNIPAR, 19, 53-58. https://doi.org/10.25110/arqsaude.v19i1.2015.5265

[27] Lazarus, R.S. and Folkman, S. (1984) Stress Appraisal and Coping. Spring Publishing Company, New York.

[28] Bowles, M.A., DeHart, D. and Webb, J.R. (2012) Family Influences on Female Offenders' Substance Use: The Role of Adverse Childhood Events among Incarcerated Women. Journal of Family Violence, 27, 681-686.

https://doi.org/10.1007/s10896-012-9450-4

[29] MacDougall, A.G., Vandermeer, M.R. and Norman, R.M. (2015) Negative Future Self as a Mediator in the Relationship between Insight and Depression in Psychotic Disorders. Schizophrenia Research, 165, 66-69. https://doi.org/10.1016/j.schres.2015.03.035

[30] Bolton, J.L., Molet, J., Ivy, A. and Baram, T.Z. (2017) New Insights into Early-Life Stress and Behavioral Outcomes. Current Opinion in Behavioral Sciences, 14, 133 139. https://doi.org/10.1016/j.cobeha.2016.12.012

[31] Targum, S.D. and Nemeroff, C.B. (2019) The Effect of Early Life Stress on Adult Psychiatric Disorders. Innovations in Clinical Neuroscience, 16, 35. 